\title{
Magnetic Proporties of Intermetallic Compounds of Praseodymium With The Metals of Iron and Renium Subgroup
}

\section{R.S. SPABEKOVA, G.SH. OMASHOVA, N.S. SAIDULLAEVA, K.SH. ABDIRAMANOVA, M. BERDIEVA and ABLYAZIMOVA NURZHAMAL MAKHAMATOVNA}

\author{
M. Auezov South Kazakhstan State University Department of "Physics for engineering specialties", \\ M. Auezov South Kazakhstan State University, 5 Tauke-khan ave., \\ Shymkent, 160000, Kazakhstan. \\ ${ }^{*}$ Corresponding author E-mail: khadi_kab@ mail.ru \\ http://dx.doi.org/10.13005/ojc/330356
}

(Received: January 25, 2017; Accepted: February 02, 2017)

\begin{abstract}
This article considers the phase structure and physical and chemical properties of alloys of systems Pr-Fe-Co, Pr-Co-Re and Pr-Fe-Re at $870 \mathrm{~K}$. The phase equilibrium in the Pr-Co-Fe, Pr$\mathrm{Co}-\mathrm{Re}, \mathrm{Pr}-\mathrm{Fe}-\mathrm{Re}$ systems is studied by the methods of physical-chemical analysis. The research results are presented in the form of isothermal cross-sections of triple phase diagrams at $870 \mathrm{~K}$ for praseodymium concentration up to 33,3 at.\%. Continuous solubility occurs between binary inter metallic compounds $\mathrm{PrCo}_{2}, \mathrm{PrFe}_{2}, \mathrm{Pr}_{2} \mathrm{Co}_{17}$ and $\mathrm{Pr}_{2} \mathrm{Fe}_{17}$ in the system of $\mathrm{Pr}-\mathrm{Co}-\mathrm{Fe}$ at $870 \mathrm{~K}$. Besides, the magnetic properties such as saturation magnetization, residual induction and coercive force of the inter metallic compounds of $\mathrm{PrCO}_{5}$ and $\mathrm{Pr}_{2} \mathrm{Me}_{17}$ doped with iron and rhenium in the system of $\mathrm{Pr}-\mathrm{Co}-\mathrm{Fe}$, Pr-Co-Re and Pr-Fe-Re are studied along with the effect of rhenium on the magnetic properties of inter metallic compounds of praseodymium with iron and cobalt.
\end{abstract}

Keywords: praseodymium, rhenium inter metallic compound, magnetic property

\section{INTRODUCTION}

One of the major problems of inorganic chemistry is the creation of new materials that meet the requirements of modern science and technology.

Materials made of inter metallic compounds of rare earth metals with iron triads are of particular interest from both the practical and theoretical point of view. Since the rare earth metals refer to $4 \mathrm{f}$ - as well as the elements of the iron subgroup to $3 d-$ transition metals, than the atoms of these elements have inner orbital with unpaired electrons that causes the occurrence of the magnetic moments. Compounds formed by rare earth metals with iron triad have complex magnetic structures resulting in strong magnetic properties. 
However, the widespread use of magnetic materials created of inter metallic compounds of the rare earth metals with metals of the iron subgroup is limited by their extreme fragility and low technology. Therefore, the search of ways of strengthening intermetallic compounds of rare earth metals and improvement of their adaptability is an extremely urgent task.

Analysis of the available data in the literature allows doing an assumption that the addition of rhenium to the rare earth intermetallic compounds improve their technological characteristics and stabilize their magnetic properties. Therefore, a systematic study of new complex compositions with praseodymium, rhenium and iron triad is very reasonable and promising.

According to the law discovered by O.Kubashevsky ${ }^{1}$, the enthalpy of formation of intermetallides of iron triad metals grows in the modulus along $\mathrm{Fe}-\mathrm{Co}-\mathrm{Ni}$ series owing to increase of acceptor abilities of elements $d$ - band in this series. As a result the number of formed intermetallides and their stability should increase at transition from Me-Fe systems to Me-Co and Me-Ni as occurs in Pr-Fe and Pr-Co systems ${ }^{2}$. O. Kubashevsky's law isn't obeyed at interaction of rhenium with iron, cobalt and nickel, namely, the number of intermetallide compounds decreases for Re-Fe and Re-Co systems ${ }^{3}$.

Taking into account the value of statistical criteria of Vozdvizhensky ${ }^{4}$ it is possible to offer that interactions between rhenium and metals of iron subgroup are rather simple. This is confirmed by formation of solid solutions of rhenium with hexagonal modification of cobalt.

\section{MATERIAL AND METHOD}

The research of alloys by means of complex methods of the physical and chemical analysis has allowed to establish the character of interaction in the ternary $\mathrm{Pr}-\mathrm{Co}-\mathrm{Fe}$ and $\mathrm{Pr}-\mathrm{Co}-\mathrm{Re}$ systems at 870 $\mathrm{K}^{5}$. The obtained results being in agreement with each other show that the interaction of components in studied systems, mainly is defined by the processes occurring in binary systems.

The analysis of the presented literary material allows to conclude that interactions of praseodymium with iron and cobalt essentially differs from interaction in Pr-Co-Re and Pr-Co-Fe systems at $870 \mathrm{~K}$.

In the studied systems we discovered practically all binary inter-metallide compounds, except $\mathrm{Pr}_{5} \mathrm{Co}_{19}$ and $\mathrm{PrRe}_{2}$ that are found in the binary limiting systems stable at $870 \mathrm{~K}$. In the ternary Pr-Co-Fe system at 870 the continuous series of solid solutions $\mathrm{PrCO}_{2}$ and $\mathrm{PrRe}_{2}, \mathrm{Pr}_{2} \mathrm{Co}_{17}$ and $\mathrm{Pr}_{2} \mathrm{Fe}_{17}$ is formed.

Hume-Rothery ${ }^{6}$ formulated three conditions of formation of a continuous series of solid solutions:

1) The crystal structure belongs to one structural type.

2) The sizes of atoms differ not greatly (the differences in values of atomic radii shouldn't exceed $10-12 \%$ ).

3) Metals are of similar chemical nature. Fulfillment of the above-stated conditions promotes to the formation of a continuous series of solid solutions in Pr-Co-Fe system.

\section{RESULT AND DISCUSSION}

The location of homogeneity areas of a continuous number of solid solutions along iso concentrates of Pr and a continuous change of lattice periods of their homogeneity area proves that there is a formation of solid solutions by replacement of one $3 d$-elements in a crystal lattice. Non-obeying of one of the conditions of a continuous number of solid solutions leads to the formation of the limited solid solutions which area of existence varies in the investigated systems in very wide limits.

The extension of homogeneity areas of the limited solid solutions on the basis of binary phases with identical stoichiometric structures in ternary system is defined basically by the dimensional factor. Thus solubility of the third component in the initial binary phases is greater if there is less distinction in the sizes of replaced and replacing atoms (fig. 1). The change of parameters of lattices in $\mathrm{PrCo}_{3}, \mathrm{Pr}_{2} \mathrm{Co}_{7}$, $\mathrm{PrCO}_{5}$ compounds shows that solubility of the third component in Pr-Co-Fe system is greater than in $\mathrm{Pr}$ - Co - Re and Pr - Fe-Re (fig. 2) systems. Within the 
separate system the solubility of the third component in compounds with various stoichiometric content can't be explained unambiguously by the properties of compounds - solvents, i.e. by thermodynamic structure or stoichiometry. The dimensional factor in this case plays a minor role in comparison with other factors. The established dependence of a solubility limit upon the constant concentration of $3 \mathrm{~d}$ - electrons in phases of $\mathrm{PrCo}_{3}, \mathrm{Pr}_{2} \mathrm{Co}_{7}$, $\mathrm{PrCO}_{5}$ allows to assume that stability of the binary compounds $\mathrm{R}_{\mathrm{x}} \mathrm{M}_{\mathrm{y}}$ with crystal structures derived from the compounds of $\mathrm{CaCu}_{5}$ type is defined by $3 d-$ electronic concentration ${ }^{7}$. The solubility of rhenium in binary inter-metallides of praseodymium with cobalt and iron is insignificant, possibly, owing to the influence of the dimensional factor of $r_{\mathrm{Fe}}=0,126 \mathrm{~nm}$, $r_{\mathrm{Re}}=0,137 \mathrm{~nm}$. research of rhenium influence on the stabilization of binary inter-metallide compounds of praseodymium with cobalt and iron by means of a complex methods of the physical and chemical analysis has shown that rhenium dissolution occurs by statistical replacement of $3 d-$ transitive metal atoms with atoms of rhenium. Since magnetic properties of these inter-metallides are defined by presence of exchange interaction in the sublattice of metals of Fe triad, then dissolution of magneticinactive atoms of $\mathrm{Re}$ in these inter-metallides should change magnetic behavior of these phases.

Study of phase structure is taken as a theoretical basis for research and a choice of alloys possessing optimum magnetic properties. On the basis of the analysis of literary and experimental

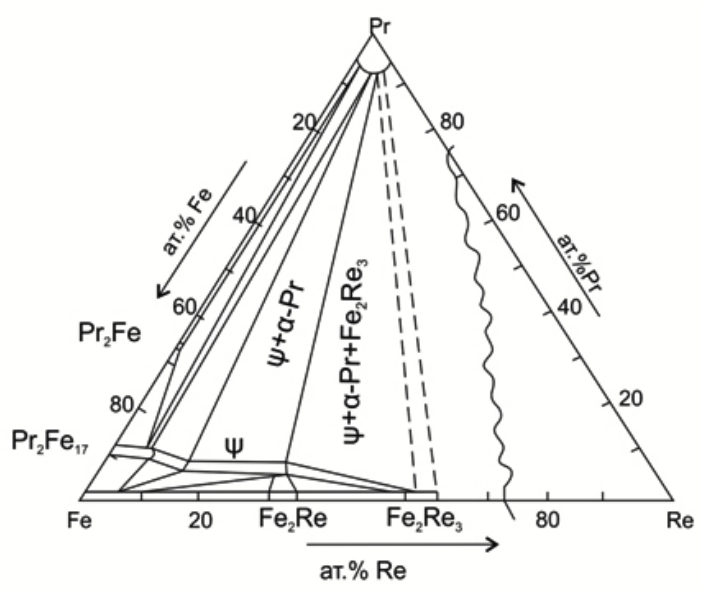

Fig. 1. Isothermal cross-section for Pr-Co-Re system at $870 \mathrm{~K}$ data it became possible to assume that alloys from area $\mathrm{PrCo}_{5}, \mathrm{Pr}_{2} \mathrm{Me}_{17}$ and new ternary inter-metallide compounds $\psi$ should possess high magnetic characteristics. Therefore the study of magnetic properties of alloys from homogeneity areas of these compounds is of great importance since such alloys can be used as magnetic materials.

Results of the magnetic analysis for Pr-CoFe system in cuts of $\mathrm{Pr}_{2} \mathrm{Me}_{17}$ and 16,6 aT. \% Pr in the homogeneity area of the inter-metallide compound $\mathrm{PrCo}_{5}$ show that the magnetic saturation and the residual induction decrease and coercive force grows. The further replacement of cobalt atoms by magnetic-active atoms of iron leads to increase in magnetic saturation and residual induction. These properties follow from the gradual filling of $3 d-$ band. As it is above mentioned the compounds $\mathrm{Pr}_{2} \mathrm{Co}_{17}$ and $\mathrm{Pr}_{2} \mathrm{Fe}_{17}$ form a continuous number of solid solutions. The saturation magnetization coincides with the maximum of the lattice periods and microhardness ${ }^{8}$. The results of the magnetic analysis for $\mathrm{Pr}-\mathrm{Co}-\mathrm{Fe}$ system are represented in the tab.1.

Results of researches show that alloys of these solid solutions are characterized by ferrimagnetic ordering ${ }^{9}$.

Doping with iron increases the saturation magnetization and residual induction. The low values of coercive force are explained by lattice defects, oxidation of the alloy surface, as well as brittleness and low adaptability of these intermetallic

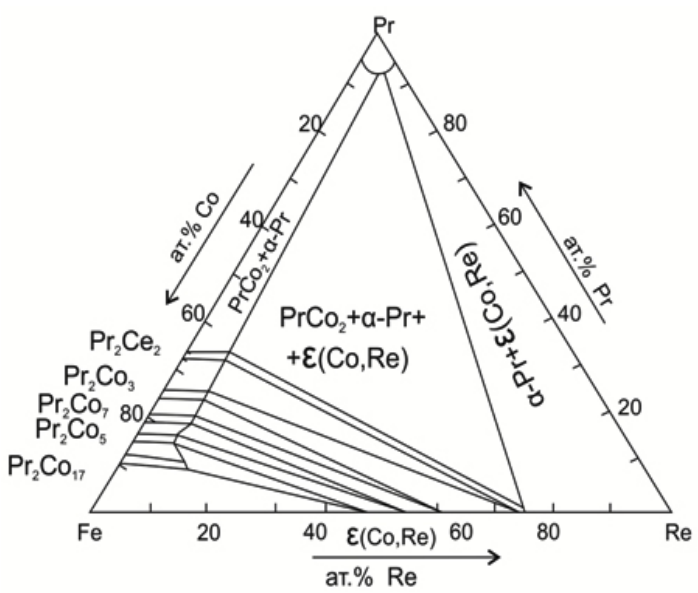

Fig. 2. Isothermal section for Pr-Fe-Re system at $870 \mathrm{~K}$ 
compounds. Therefore more refractory alloys of rhenium must improve manufacturability of these intermetallic compounds. The results of the magnetic analysis for Pr-Co-Re system are represented in the tab.2. According to the research results substitution of Co atoms by magneto-inactive $\mathrm{Re}$ atoms leads to the decrease of the saturation magnetization and residual induction, but the coercive force of Re system increases monotonically. The reason for such an increase of the coercive force of alloys is the change of the phase composition.

In the Pr-Fe-Re system the study of the Re effect on the magnetic properties of intermetallic

Table 1. The results of magnetic analysis of Pr-Co-Fe system with a constant content of $\mathrm{Pr}-16.6$ at.\% and in section of $\mathrm{Pr}_{2} \mathrm{Co}_{17}-\mathrm{Pr}_{2} \mathrm{Fe}_{17}$, in the field of $20 \mathrm{kA} / \mathrm{m}$.

\begin{tabular}{|c|c|c|c|c|c|c|}
\hline \multirow[t]{2}{*}{$N_{0}$} & \multicolumn{3}{|c|}{ Alloy composition, at. $\%$} & \multirow{2}{*}{$\begin{array}{c}\text { Saturation } \\
\text { magnetization, } \\
\mathrm{T} \text {. }\end{array}$} & \multirow{2}{*}{$\begin{array}{c}\text { Residual } \\
\text { induction, T. }\end{array}$} & \multirow{2}{*}{$\begin{array}{l}\text { Coercive force, } \\
\mathrm{A} / \mathrm{m} .\end{array}$} \\
\hline & $\mathrm{Pr}$ & Co & $\mathrm{Fe}$ & & & \\
\hline 1 & 16,6 & 83,4 & 0 & 1,4090 & 0,1135 & 10348,0 \\
\hline 2 & 16,6 & 80,0 & 3,4 & 1,1350 & 0,0680 & 11940,0 \\
\hline 3 & 16,6 & 40,0 & 43,4 & 1,3500 & 0,0890 & 10348,0 \\
\hline 4 & 10,5 & 80,0 & 9,5 & 1,1740 & 0,0767 & 10188,8 \\
\hline 5 & 10,5 & 60,0 & 29,5 & 1,2510 & 0,0830 & 9950,0 \\
\hline 6 & 10,5 & 50,0 & 39,5 & 1,4410 & 0,0995 & 12099,2 \\
\hline 7 & 10,5 & 30,0 & 59,5 & 1,4530 & 0,0785 & 10984,8 \\
\hline 8 & 10,5 & 20,0 & 69,5 & 1,4400 & 0,0785 & 10348,0 \\
\hline 9 & 10,5 & 10,0 & 79,5 & 1,1720 & 0,0780 & 10984,8 \\
\hline 10 & 10,5 & 0 & 89,5 & 0,9880 & 0,0475 & 9552,0 \\
\hline 11 & 22,2 & 77,8 & 0 & 0,8400 & 0,1870 & 27860,0 \\
\hline 12 & 12,5 & 10,0 & 77,5 & 0,1055 & 0,0575 & 11940,0 \\
\hline
\end{tabular}

Table 2. The results of magnetic analysis of Pr-Co-Re system with constant content of Pr-16.6 at. \% and 10.6 at. $\%$ in the field of $20 \mathrm{kA} / \mathrm{m}$.

\begin{tabular}{|c|c|c|c|c|c|c|}
\hline \multirow[t]{2}{*}{$\mathbf{N}_{0}$} & \multicolumn{3}{|c|}{ Alloy composition, at. $\%$} & \multirow{2}{*}{$\begin{array}{l}\text { Saturation } \\
\text { magnetization, } T \text {. }\end{array}$} & \multirow{2}{*}{$\begin{array}{l}\text { Residual } \\
\text { induction, T. }\end{array}$} & \multirow{2}{*}{$\begin{array}{l}\text { Coercive force, } \\
\mathrm{A} / \mathrm{m} \text {. }\end{array}$} \\
\hline & $\mathrm{Pr}$ & Co & $\mathbf{R e}$ & & & \\
\hline 1 & 16,6 & 83,4 & 0 & 1,3300 & 0,2480 & 29054,0 \\
\hline 2 & 16,6 & 75,0 & 8,4 & 0,8085 & 0,2120 & 29133,6 \\
\hline 3 & 16,6 & 70,0 & 13,4 & 0,7870 & 0,2180 & 45372,0 \\
\hline 4 & 16,6 & 60,0 & 23,4 & 0,5100 & 0,1660 & 49352,0 \\
\hline 5 & 16,6 & 50,0 & 33,4 & 0,3500 & 0,0740 & 76416,0 \\
\hline 6 & 10,6 & 89,4 & 0 & 1,4000 & 0,0870 & 7164,0 \\
\hline 7 & 10,6 & 85,0 & 4,4 & 1,1335 & 0,0792 & 7482,4 \\
\hline 8 & 10,6 & 80,0 & 9,4 & 0,8790 & 0,1165 & 26745,6 \\
\hline 9 & 10,6 & 70,0 & 19,4 & 0,8130 & 0,2930 & 75620,0 \\
\hline 10 & 10,6 & 65,0 & 24,4 & 0,4850 & 0,1770 & 86366,0 \\
\hline 11 & 10,6 & 55,0 & 34,4 & 0,3900 & 0,0815 & 79202,0 \\
\hline 12 & 10,6 & 40,0 & 49,4 & 0,5440 & 0,1387 & 46008,8 \\
\hline
\end{tabular}


Table 3. The results of magnetic analysis of Pr-Fe-Re system with a constant content of Pr- 10.6 and 8.0 at. \%. in the field of $20 \mathrm{kA} / \mathrm{m}$.

\begin{tabular}{|c|c|c|c|c|c|c|}
\hline \multirow[t]{2}{*}{$\mathbf{N}_{0}$} & \multicolumn{3}{|c|}{ Alloy composition, at. $\%$} & \multirow{2}{*}{$\begin{array}{c}\text { Saturation } \\
\text { magnetization, } \mathrm{T} \text {. }\end{array}$} & \multirow{2}{*}{$\begin{array}{l}\text { Residual induction, T. } \\
\text { induction, } \mathrm{T} \text {. }\end{array}$} & \multirow{2}{*}{$\begin{array}{l}\text { Coercive force, } \\
\mathrm{A} / \mathrm{m}\end{array}$} \\
\hline & $\mathbf{P r}$ & $\mathrm{Fe}$ & $\mathrm{Re}$ & & & \\
\hline 1 & 10,5 & 89,5 & 0 & 0,5000 & 0,0550 & 15920 \\
\hline 2 & 10,5 & 84,5 & 5,0 & 0,7000 & 0,0600 & 31840 \\
\hline 3 & 10,5 & 79,5 & 10,0 & 0,2000 & 0,0410 & 6368 \\
\hline 4 & 10,5 & 74,5 & 15,0 & 0,4000 & 0,0700 & 7562 \\
\hline 5 & 8,0 & 77,0 & 15,0 & 0,1000 & 0,0510 & 7960 \\
\hline 6 & 8,0 & 72,0 & 20,0 & 0,4000 & 0,0800 & 19900 \\
\hline 7 & 8,0 & 67,0 & 25,0 & 0,7000 & 0,0850 & 31840 \\
\hline 8 & 8,0 & 62,0 & 30,0 & 0,9000 & 0,0900 & 36616 \\
\hline
\end{tabular}

compounds $\mathrm{Pr}_{2} \mathrm{Fe}_{17}$ and new ternary intermetallic compounds $\psi$ showed that in homogeneity area their saturation magnetization, residual induction and coercive force increase monotonically ${ }^{10}$ (Table 3.).

\section{CONCLUSION}

Alloys of phase area $\mathrm{Pr}_{2} \mathrm{Me}_{17}$ in the Pr$\mathrm{Co}-\mathrm{Fe}$ and $\mathrm{PrCo}_{5}+\mathrm{Pr}_{2} \mathrm{Co}_{7}+\varepsilon$ (Co, Re) system with optimal combination of magnetic properties (saturation magnetization, residual induction, coercive force) can be recommended for the production of magnetic materials

\section{REFERENCES}

1. Kubaschewski, O.; Chart, T.C. J. Inst. Metals. 1965, 93, 329-338

2. Moffat W.G. The handbook of binary phase diagrams. General Electric Comp. 1981

3. Parthe E.; Moreau J.M. J. Rare-earth metals. 1977, 53, 1-24

4. Vozdvijenski V.M. Forecast of binary phase diagrams. l̀.: Metallurgy. 1975, 224.

5. Spabekova R.S.; Sokolovskaya E.M.; Vetoshkin I.D.; Kazakova E.F. Phase structure and properties of alloys of the system praseodymium-cobalt-iron. Herald of Moscow State University. 1992, 33, ${ }^{13}$.

6. Hume-Rothery W. Factors influencing stability of metal phases. Collection of articles: Stability of phases in metals and alloys. ì.: World. 1970, 197-199.

7. Sokolovskaya E.M.; Vetoshkin I.D.; Kazakova E.F.; Spabekova R.S. Formation of intermetallides in praseodymium-iron-cobalt system. VI Conference on a crystal chemistry of inorganic and coordination compound. 1992, 227.

8 Sokolovskaya E.M.; Vetoshkin I.D.; Kazakova E.F.; Spabekova R.S. Phase structure and properties of alloys of the system Pr- Nî- Re. Herald of Moscow State University. 1992, $33,{ }^{1} 6,551-555$.

9. Spabekova R.S. Study of magnetic saturation and residual induction of the system praseodymium -cobalt-iron ( $\mathrm{Pr}-\mathrm{Co}-\mathrm{Fe})$ at $870 \hat{E}$. Science and Knowledge of South Kazakhstan. 2008, 4 (69), 57-61.

10. Spabekova R.S., Chamza A.K., Umurzahova Zh.V. Structure and stability of praseodymium compounds with transition metals. "Key problems of modern physics". Materials of the international scientific conference. Almaty. 2012. .75-78. 